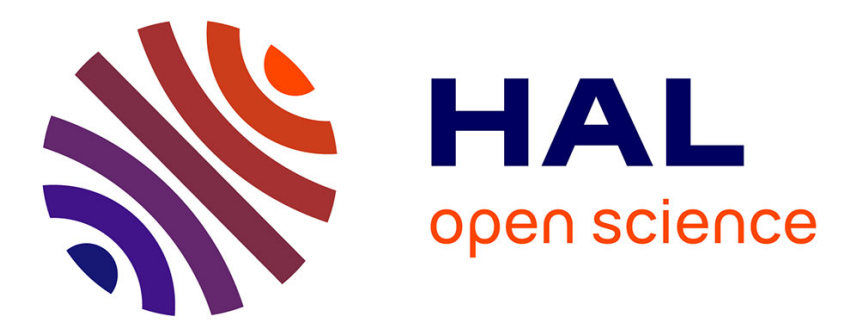

\title{
Effect of swelling level on fatigue lifetime of filled nitrile rubber
}

\author{
Mei Sze Loo, Andri Andriyana, Jean-Benoit Le Cam, Eric Robin
}

\section{To cite this version:}

Mei Sze Loo, Andri Andriyana, Jean-Benoit Le Cam, Eric Robin. Effect of swelling level on fatigue lifetime of filled nitrile rubber. 9th European Conference on Constitutive Models for Rubber (ECCMR IX), Sep 2015, Prague, Czech Republic. pp.455-460. hal-01136558

\section{HAL Id: hal-01136558 https://hal.science/hal-01136558}

Submitted on 1 Jun 2020

HAL is a multi-disciplinary open access archive for the deposit and dissemination of scientific research documents, whether they are published or not. The documents may come from teaching and research institutions in France or abroad, or from public or private research centers.
L'archive ouverte pluridisciplinaire HAL, est destinée au dépôt et à la diffusion de documents scientifiques de niveau recherche, publiés ou non, émanant des établissements d'enseignement et de recherche français ou étrangers, des laboratoires publics ou privés. 


\title{
Effect of swelling level on fatigue lifetime of filled nitrile rubber
}

\author{
M.S. Loo \& A. Andriyana \\ Department of Mechanical Engineering, University of Malaya, Kuala Lumpur, Malaysia \\ J.-B. Le Cam \& E. Robin \\ Institut de Physique de Rennes, UMR CNRS 6251, Université de Rennes 1, Rennes Cedex, France
}

\begin{abstract}
Elastomer has been used as an engineering component in various fields and in some particular cases, the material is exposed to aggressive solvents such as biodiesel during the service. The study of the durability of elastomer in the presence of biodiesel is essential, especially when biodiesel has its potential in substituting the conventional diesel in the future. The present paper investigates the effect of swelling level on the mechanical response of swollen rubbers by palm biodiesel, under fatigue loading. Two swelling levels are considered. The fatigue tests are conducted on both dry and swollen rubbers at various maximum stretch values and a constant zero loading ratio. FESEM analysis is carried out to investigate the physical fatigue damage mechanism induced in the swollen rubber. The fatigue lifetime curves revealed that swollen rubbers have a shorter lifetime compared to the dry ones. However, the swelling level might induce an effect when the crack nucleates up to a certain size, which is $1 \mathrm{~mm}$ for our case. FESEM results showed that the swelling level has no effect on the morphology of crack nucleation and propagation, regardless of the loading condition.
\end{abstract}

\section{INTRODUCTION}

In many engineering applications, the elastomeric part has to endure repetitive fluctuating loadings during the service. The elastomer eventually experience fatigue failure under such loading condition (Cadwell et al. 1940). Mars (2001) identified two distinct phases during the process of fatigue failure. The first phase is the duration of the crack nucleation from free observable macrocracks. The second phase is followed by the propagation of the crack up to failure. Later on, the study of fracture behavior of rubber by few researchers (Mars and Fatemi 2003; Le Cam et al. 2008; Le Cam et al. 2013) revealed that the appearance of a particular macroscopic crack is a consequence of the microscopic crack propagation initiating from the pre-existing flaws in the virgin material. Indeed, the studies of fatigue in elastomers offer a high challenge in the mechanics of materials due to complex interactions between the matrix, fillers, plasticizers and other additives.

In the recent era, researches have broadened their investigations in fatigue to swollen elastomers (Cho et al. 2000; Jerrams et al. 2008; Loo et al. 2015). Yet, the number still remains scarce even though the study of the effect of solvents, particularly biodiesel, on elastomers received much attention among researchers. The research in biofuels have been deemed relevant since the awareness of source depletion in conventional fuel has been risen. Biofuels has been proposed as a potential alternative energy source to replace the existing depleting fuel sources, with biodiesel as a substitute for diesel. This condition therefore creates a complex situation when the fatigue study in dry rubber itself is yet established. Moreover, the compatibility between biodiesel and elastomeric components remains as a major challenge up to this date (Haseeb et al. 2010). Many previous studies have demonstrated the degradation of properties in elastomers through swelling (Chai et al. 2011; Andriyana et al. 2012; Chai et al. 2013). Hence, the study on the fatigue of swollen elastomers compromises not only with the loading effect but also the swelling effect. From this perspective, the importance to carry out studies in this field is highlighted in order to understand the compatibility and durability of elastomer to be applied in fatigue applications. This is all the more true that up to now the effect of swelling level on fatigue of rubber has not been extensively studied. The present paper proposes the first attempt to investigate the effect of swelling level, due to exposure to palm biodiesel, on the mechanical response of elastomers under fatigue loading conditions. 


\section{EXPERIMENTAL PROGRAM}

The material investigated is a commercial grade of carbon black-filled natural rubber with 60 shore hardness and $25 \mathrm{wt} \%$ of carbon-black. The diabolo rubber specimens have a height, outer diameter, and wall thickness of $55 \mathrm{~mm}, 25 \mathrm{~mm}$, and $6 \mathrm{~mm}$ respectively. The swollen rubber specimens are obtained by immersing dry specimens in biodiesel for 3 days and 10 days respectively to achieve a $3 \%$ and $5 \%$ volume change. The swelling level $J_{s}$ denotes the volume ratio of the swollen rubber. No standard is followed regarding the choice of the specimens of immersion durations.

The fatigue tests were conducted using a $5 \mathrm{kN}$ Shimadzu 4830 fatigue testing machine with the load cell capacity of $5 \mathrm{kN}$. The rubbers were subjected to a prescribed sinusoidal displacement under uniaxial tension mode at room temperature with. The nominal strain ratio or loading ratio, $R_{\varepsilon}$ is defined as the ratio between the minimum strain, $\left(\varepsilon_{\text {min }}\right)$ and the maximum $\left(\varepsilon_{\max }\right) . R_{\varepsilon}$ is set to be zero throughout the experiment by imposing the maximum stretch values of $1.5,1.75,1.9$ and 2 , while the minimum stretch remains zero. In the current investigation, the stretch is defined by the ratio between the current lengths to the initial length of the rubber specimen. In the case of swollen rubber, the specimen initial length corresponds to the swollen-unstrained length. Being the first approach, thermal effects were undesirable. Hence, the strain rate of the material is constrained to be within the range of $1 s^{-} 1 \leq \dot{\lambda} \leq 2.5 s^{-} 1$. The frequency imposed for all loading conditions is $1 \mathrm{~Hz}$ except for the maximum stretch of 1.5 , where a $2 \mathrm{~Hz}$ is applied. Two tests are completed for each loading condition.

\section{RESULTS AND DISCUSSION}

\subsection{Stress-stretch response}

The general mechanical response at each cycle for both dry and swollen rubber is ascertained to be comparable at each loading condition. Consequently, only stretch-stress plots for the 10th and 100th cycle are shown in Figure 1 and Figure 2 for maximum stretch of 1.5 and 2 respectively. The stress decreases as the number of cycles increase for both dry and swollen rubber regardless of the imposed maximum stretch. This is due to the softening effect and some of the proposed phenomena to interpret the stres-softening mechanism by researchers are: irreversible breakage of polymer chains or cross links in the elastomer network (Mars 2001), interactions between fillers and rubber matrix, the reorganization of the filler network and the viscoelasticity of the macromolecular
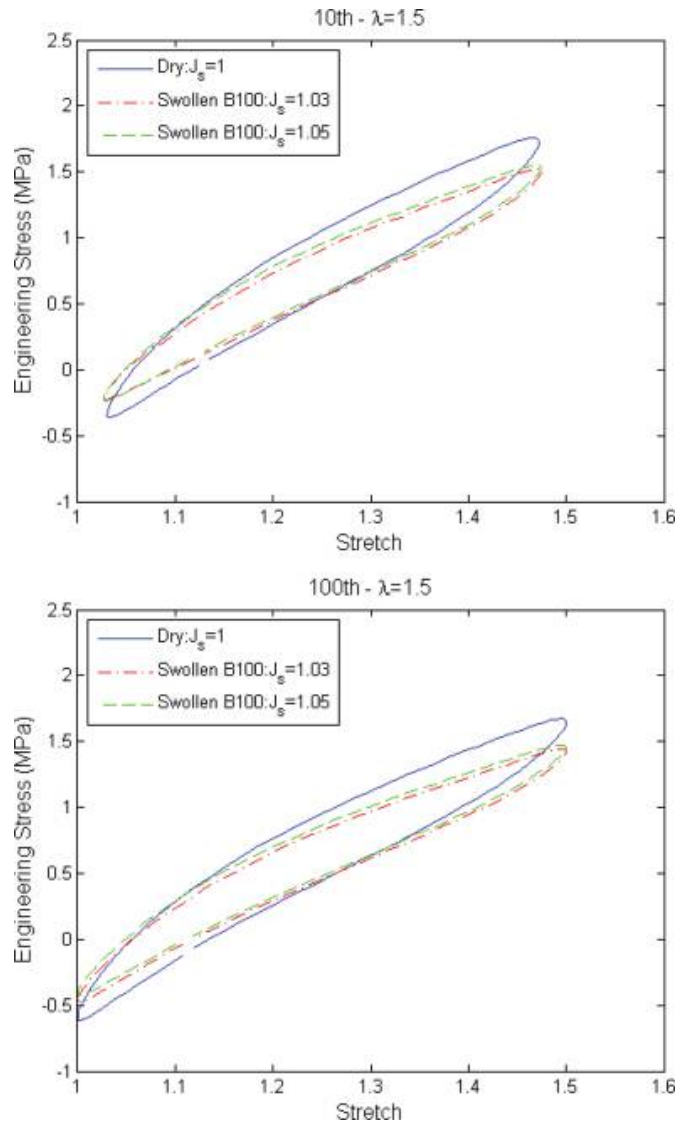

Figure 1. The stretch-stress responses of dry and swollen rubber at maximum stretch of 1.5 .

network in the rubbery state. The lower mechanical response observed in swollen rubbers is due to the degradation of properties of the elastomer as a result of exposure to biodiesel, and it has already been reported in a few number of works (Chai et al. 2011; Andriyana et al. 2012; Chai et al. 2013).

Comparing the stretch-stress plots between Figure 1 and Figure 2, the mechanical response between dry and swollen rubber becomes closer as the imposed maximum stretch is higher at a given number of cycles. For instance, a significant lower stress value is needed to stretch the specimen compared to the dry state for the 10th and 100th cycle at $\lambda=1.5$. Meanwhile, the amount of stress needed to stretch the rubber at $\lambda=2$ is almost similar for both dry and swollen rubber. Since swelling increases the volume of the rubber, the number of the molecular chains per unit volume decreases. Subsequently, the energy per unit volume needed to deform the swollen rubber decreases and this is especially for the case at lower stretch values. The concentration 

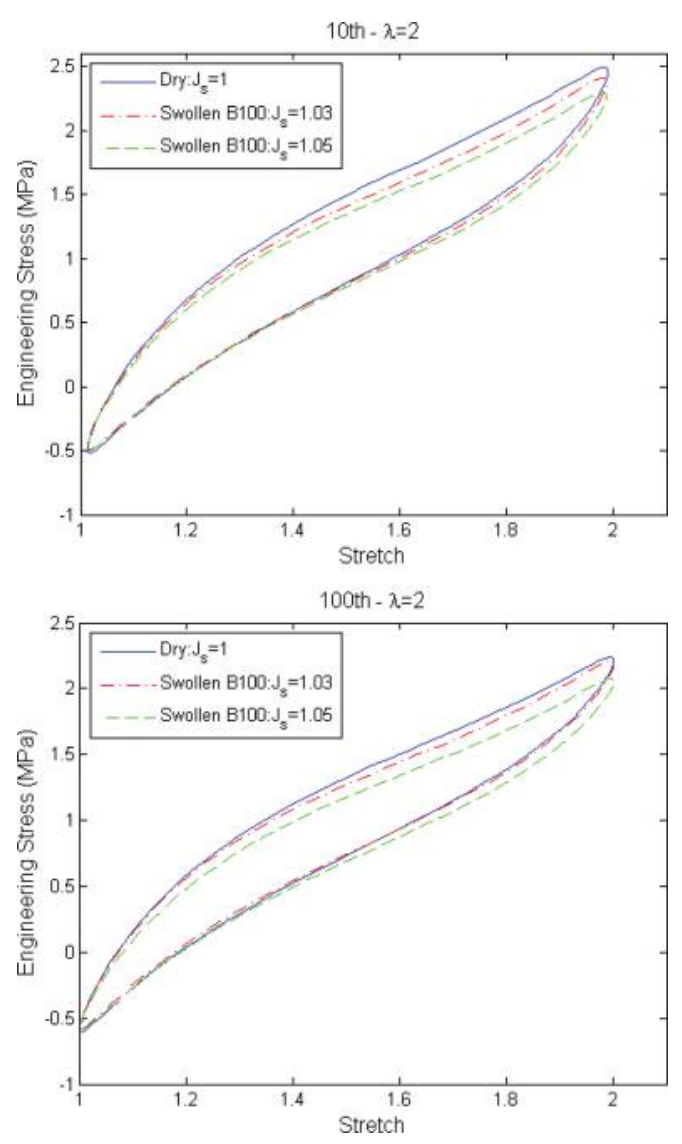

Figure 2. The stretch-stress responses of dry and swollen rubber at maximum stretch of 2 .

of network chains becomes an important consideration when Horkay and Lin (2009) revealed that concentration of network chains is the main contribution to the modulus or stiffness of a swollen polymer network, instead of the interaction between the polymer and the solvent.

An almost similar responses observed between dry and swollen rubbers at higher stretch values suggest that the dominant effect on the stiffness of swollen rubber is attributed to the extensibility of the polymer chains, instead of swelling. This trend is also observed at higher amount of cycles. The stretchstress response at the crack nucleation, $N_{i}$, cycles in Figure 3 shows that even though the $N_{i}$ is different for both swollen and dry rubber, the stretch-stress response is almost identical at the stretch value of 2 .

\subsection{Evolution of peak stress}

In each number of cycles, the peak stresses are identified and the evolutions of the peak stress

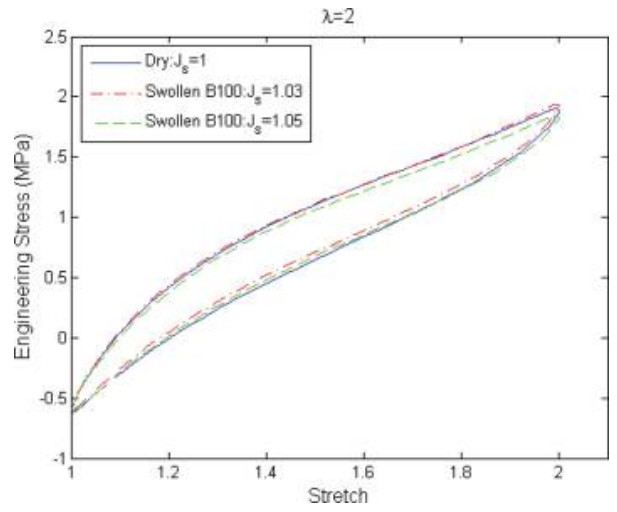

Figure 3. The stretch-stress response of dry and swollen rubber at crack nucleation for maximum stretch of 2 .
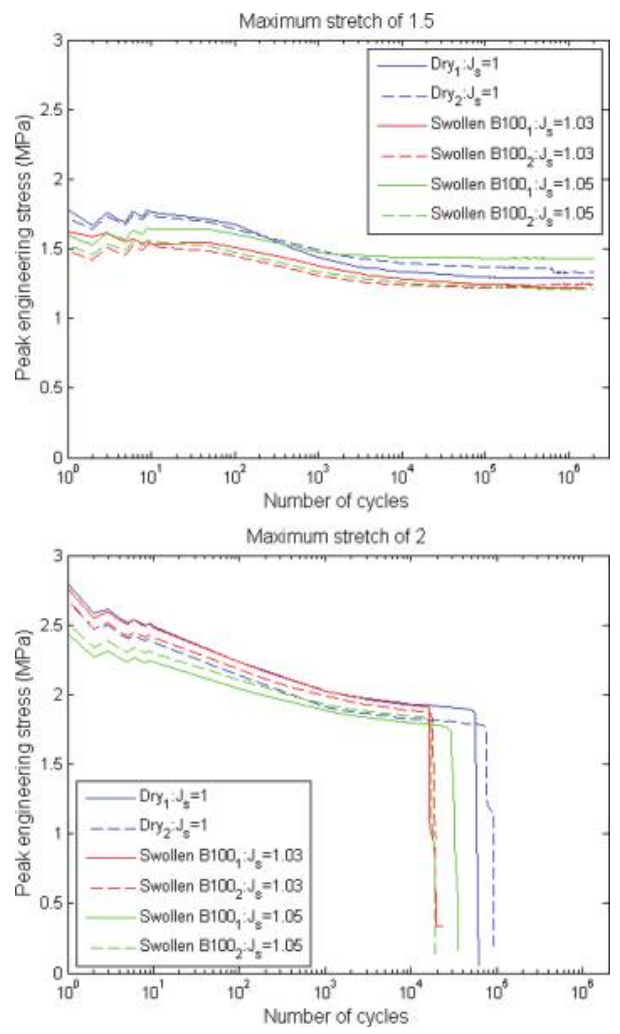

Figure 4. Evolutions of peak stress as a function of number of cycles at maximum stretches of 1.5 and 2 .

versus the number of cycles are depicted in Figure 4 for the lowest and highest maximum stretch. In Figure 4, a particular fluctuations is observed for the first few cycles due to the limitation of the machine. The value of stresses decreases 
progressively throughout the test until it undergoes a sharp drop at the end of test. Noted that this sharp drop is not observed for all tests conducted at $\lambda=1.5$ since no rupture has taken place. Hence, for the sake of feasibility for this research work, the end-of-life for such condition is set to be at 2 million cycles. No stabilized stress response was observed at any point throughout the entire tests. This leads to having the maximum stretch as the only possible predictor at this stage of research for the fatigue lifetime curve.

\subsection{Fatigue lifetime}

The fatigue lifetime curves are plotted with the maximum stretch versus the number of cycles to failure shown in Figure 5. The end-of-life definition used is the appearance of a $1 \mathrm{~mm}$ crack size and complete rupture. In both of these figures, the best power law fit to predict the lifetime is also
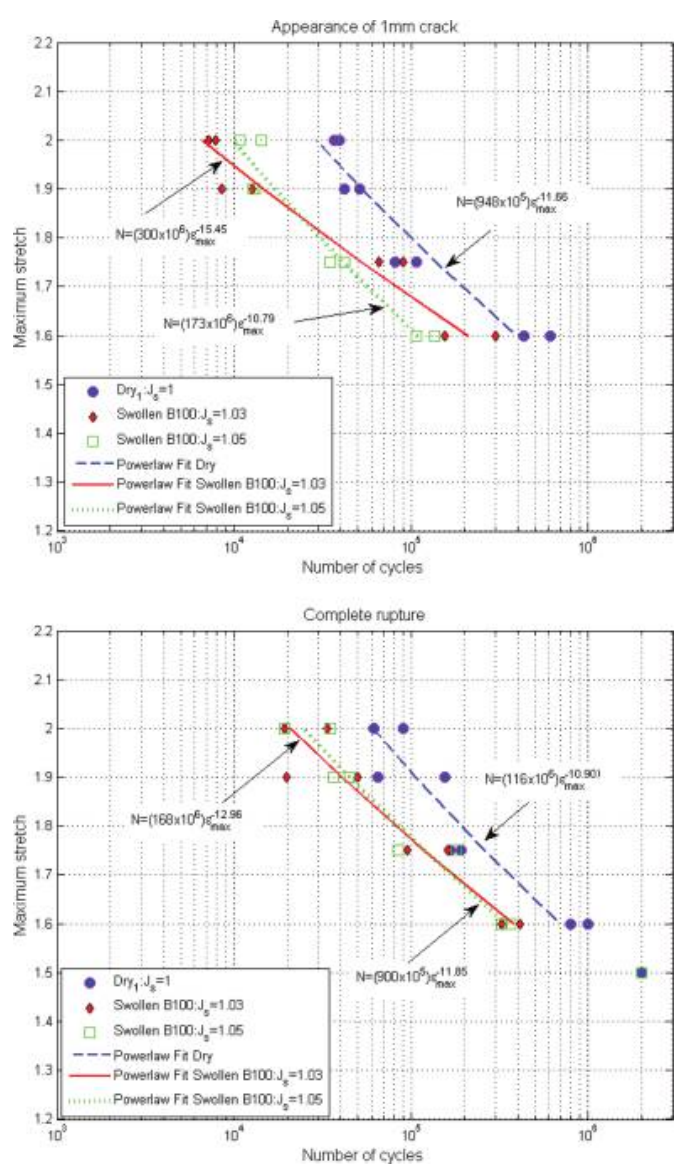

Figure 5. $\lambda$-N curves at appearance of a $1 \mathrm{~mm}$ crack size and complete rupture. included for both dry and swollen rubbers. It is observed that the dry rubber took the longest time for the appearance of a $1 \mathrm{~mm}$ crack size at all loading conditions. At lower maximum stretches than $\lambda=1.75$, the lifetime of swollen rubber appears to be closer to the dry rubber when compared to a higher maximum stretch values. Generally, the lifetime swollen rubber at $J_{s}=1.05$ seems to be the shortest, similar and longer at $\lambda=1.75,1.9$ and 2 respectively when compared to the swollen rubber at $J_{s}=1.03$.

The overall lifetime at complete rupture for all swollen rubbers appears to be relatively similar regardless of the different swelling. These discrepancies seem to indicate that even though the swelling level influences the duration of crack nucleation, it does not affect significantly the crack propagation duration. The lifetime of the swollen rubber is always lower than the dry rubber due to the induced physical and chemical changes whenever rubbers are exposed to biodiesel (Richaud et al. 2013). The two mechanisms (chemical and physical) are interrelated whereby one mechanism eventually leads to another, disregarding whichever initiates first.

\subsection{FESEM observation}

\subsubsection{Analysis at the macroscopic scale}

An example of ruptured dry rubber specimen is shown in Figure 6. It is to note that these features are relatively similar to swollen rubber regardless of the loading condition. In this figure, the generated crack propagation plane is circled in red solid line. It is observed that the crack propagation plane is not perpendicular to imposed loading. This observation could be related to the hollow geometry of the specimen, which induces a complex crack propagation direction. At this plane, investigations are carried out at the microscopic scale to observe the morphologies of crack nucleation location and crack propagation.

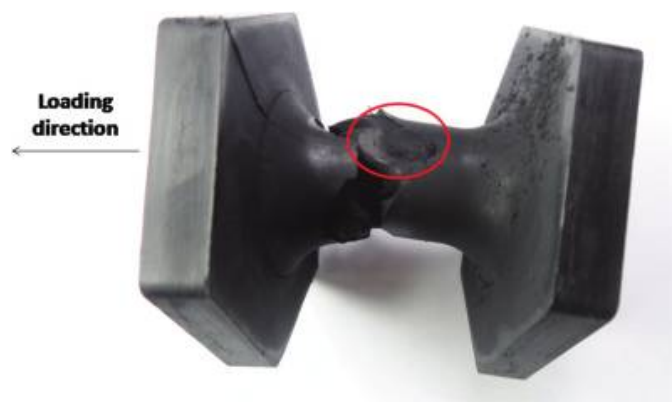

Figure 6. Ruptured dry specimen. 


\subsubsection{Analysis at the microscopic scale}

At this scale, the analysis is performed through FESEM to first compare the rubber surface at the dry un-stressed and swollen un-stressed state. Figure 7 and Figure 8 shows the micrographs obtained at the surface for dry and swollen rubber (B100) respectively. The surface of the swollen B100 rubber appears to be smoother than the dry rubber. Huge amount of particles seem to be present throughout the swollen rubber surface due to the induced extraction of soluble components from the rubber (Trakarnpruk and Porntangjitlikit 2008; Richaud et al. 2013).

The discussion for the obtained results is detailed in two categories, the crack nucleation and crack propagation.

Crack nucleation The analyzed fracture surface for both dry and swollen rubbers at all loading

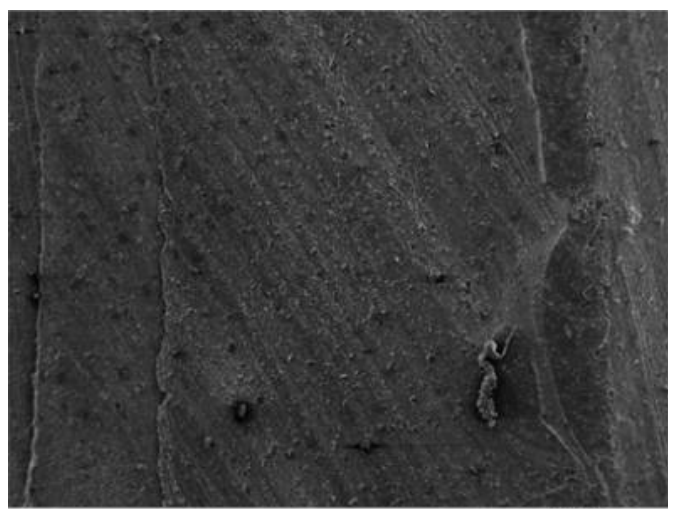

$250 \mu \mathrm{m}$

Figure 7. Surface of dry rubber.

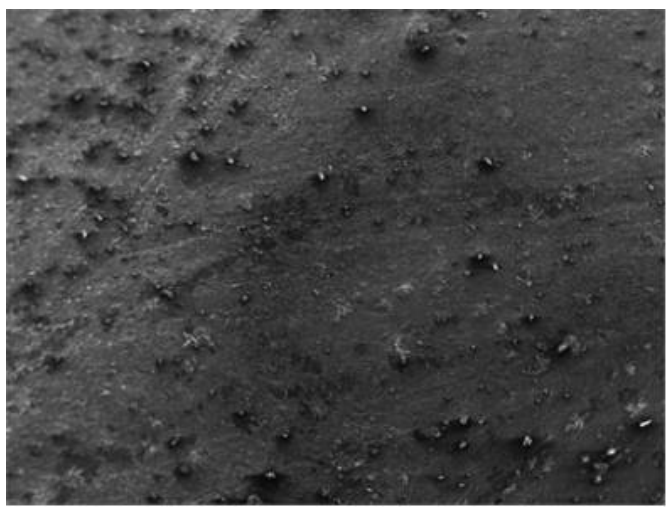

$250 \mu \mathrm{m}$

Figure 8. Surface of swollen B100 rubber.
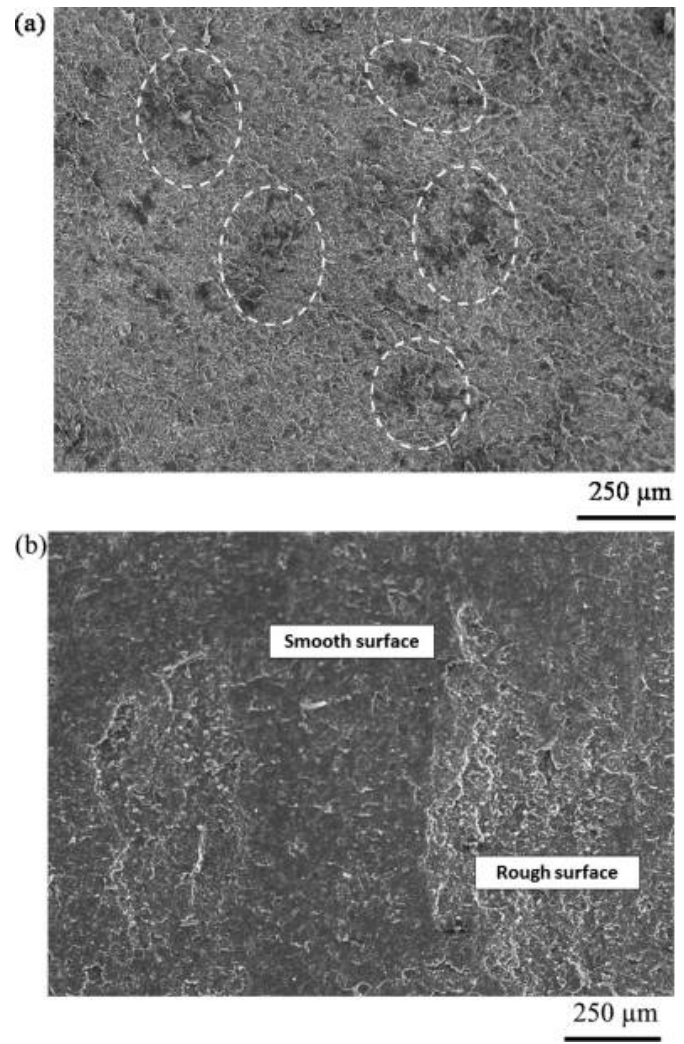

Figure 9. Types of smooth surfaces in swollen B100 rubber.

conditions reveals that the crack nucleates at the surface of the specimen instead at the sub-surface. Furthermore, it is deduced that the stress concentration is highest at this site. No similar particles or agglomerates which were previously observed by other researchers were identified (Saintier et al. 2006; Le Cam et al. 2013; Le Cam et al. 2014).

Crack propagation Similar propagation patterns have been observed in both dry and swollen rubbers. A particular feature named as Clouded Wool (CW) in the previous work of Loo et al. (2015) is recognized. Smooth surface are only observed in swollen rubber and it is present either in scattered (see circled zone in the white dashed line) or patches as shown in Figure 9(a) and Figure 9(b) respectively.

\section{CONCLUSIONS}

The effect of swelling level on the nitrile rubber under uniaxial fatigue loading has been investigated. The lifetime of the swollen rubber is 
shorter than the dry rubber regardless of the type of imposed maximum stretch value. However, the swelling level might induce an effect when the crack nucleates up to a certain size, which is $1 \mathrm{~mm}$ for this case. On the other hand, no significant difference is observed in the fractography analysis at the macro and microscale scales for both dry and swollen rubber, at the crack initiation and propagation zone. Even though crack initiates at the specimen surface, it is found that the crack nucleation pattern is not distinguishable for all investigated specimens. In fact, the effect of loading on the morphology of cracks is not noticeable on all of the fracture surface specimens. Future works on the study of the influence of different loading ratios and formulations on swollen rubber should be considered in order to understand further the behavior of rubber under fatigue condition.

\section{ACKNOWLEDGEMENT}

The authors greatly appreciate the financial support from Ministry of Higher Education Malaysia through High Impact Research Grant HIRMOHE D000008-16001.

\section{REFERENCES}

Andriyana, A., A.B. Chai, E. Verron, and M.R. Johan (2012). Interaction between diffusion of palm biodiesel and large strain in rubber: Effect on stress-softening during cyclic loading. Mech. Res. Commun 43, 80-86.

Cadwell, S., R. Merrill, C. Sloman, and F. Yost (1940). Dynamic fatigue life of rubber. Ind. Eng. chem. 12(1), $19-23$.

Chai, A.B., A. Andriyana, E. Verron, and M.R. Johan (2013). Mechanical characteristics of swollen elastomers under cyclic loading. Mater. Design 44, 566-572.

Chai, A.B., A. Andriyana, E. Verron, M.R. Johan, and A.S.M.A. Haseeb (2011). Development of a compression test device for investigating interaction between diffusion of biodiesel and large deformation in rubber. Polym. Test. 30, 867-875.
Cho, K., W. Jang, D. Lee, H. Chun, and Y. Chang (2000). Fatigue crack growth of elastomers in the swollen state. Polymer 41(1), 179-183.

Haseeb, A.S.M.A., H.H. Masjuki, C.T. Siang, and M.A. Fazal (2010). Compatibility of elastomers in palm biodiesel. Renew. Energ. 35, 2356-2361.

Horkay, F. and D. Lin (2009). Mapping the local osmotic modulus of polymer gels. Langmuir 25(15), 8735-8741.

Jerrams, S., J. Hanley, N. Murphy, and H. Ali (2008). Equi-biaxial fatigue of elastomers: The effect of oil swelling on fatigue life. Rubber Chem. Technol. 81(4), 638-649.

Le Cam, J.-B., B. Huneau, and E. Verron(2008). Description of fatigue damage in carbon black filled natural rubber. Fatigue Fract. Eng. M. 31(12), 1031-1038.

Le Cam, J.-B., B. Huneau, and E. Verron (2013). Fatigue damage in carbon black filled natural rubber under uni-and multiaxial loading conditions. Int. J. Fatigue.

Le Cam, J.-B., B. Huneau, and E. Verron (2014). Failure analysis of carbon black filled styrene butadiene rubber under fatigue loading conditions. Plast. Rubber Compos. 43(6), 187-191.

Loo, M. S., J.-B. Le Cam, A. Andriyana, E. Robin, and A. Afifi (2015). Fatigue of swollen elastomers. Int. J. Fatigue 74, 132-141.

Mars, W. and A. Fatemi (2003). Fatigue crack nucleation and growth in filled natural rubber. Fatigue Fract. Eng. M. 26(9), 779-789.

Mars, W.V. (2001). Multiaxial fatigue of rubber. Ph. D. thesis, University of Toledo.

Richaud, E., F. Djouani, B. Fayolle, J. Verdi, and B. Flaconneche (2013). New insights in polymer-biofuels interaction. Oil \& Gas Science and Technology-Revue d'IFP Energies nouvelles.

Saintier, N., G. Cailletaud, and R. Piques (2006). Crack initiation and propagation under multiaxial fatigue in a natural rubber. International journal of fatigue 28(1), $61-72$.

Trakarnpruk, W. and S. Porntangjitlikit (2008). Palm oil biodiesel synthesized with potassium loaded calcined hydrotalcite and effect of biodiesel blend on elastomer properties. Renew. Energ. 33, 1558-1563. 